Gülcan Eraktan, Janusz Gudowski, Emine Olhan

\title{
RURAL TRANSFORMATION. SAMPLE SURVEY ANALYSIS
}

Just like rural life and rural structure, the farming system and methods in Turkey are also subject to change. Mechanisation increased, irrigation and inputs use became widespread, marketing of agricultural products developed. Transformation is seen in every fragment of the rural sector across the country.

We have seen the effects of all these processes within the research area as well. Though the development of the settlements visited by Prof. Leszczycki in the late 1930s varies, the main characteristics of the inhabitants are, however, similar, including the general approach concerning production and marketing patterns, or the enthusiasm for increasing productivity since the climate and soil conditions are proper for horticultural activities. Farmers who have an access to irrigation facilities produce fruits and vegetables in all of the investigated villages. Therefore, the need for increasing irrigation is continuing with respect to both surface and artesian water. Similar active attitude may be observed in case of dealing with the produce.

Depending on financial possibilities farmers sell their products either at the market in the neighbouring towns personally or they sell products to merchants who visit the villages and buy agricultural produce directly from the farmer. The latter case, though comfortable, may be sometimes disadvantageous if farmers do not have bargaining talents.

\section{SOCIAL AND ECONOMIC STRUCTURE OF THE HOUSEHOLDS*}

Interviewed inhabitants can be characterised from many points of view. $21 \%$ of farmers (out of the total of 80 ) are below the age of 40 while $43 \%$ are between $41-60$ years of age. The remaining $36 \%$ are older than 60 . It seems that the age structure is dominated by the older stratas though in fact the

\footnotetext{
* Preliminary analysis based on interviews completed in 16 villages in November 1997 for the total 240 persons ( 80 male farmers, 80 women and 80 youth). For the list of the villages see the report "Research origin and its organisation".
} 
main reason for the absence of younger farmers in the sample is exactly their work in the fields and gardens or at the market in towns during our visit.

Educational level is an important factor in social and economic development of rural society. Education and training make the acceptance of the innovations and the adjustment to the changes is much easier. $77.5 \%$ of the interviewed householders graduated from the primary schools (5 years of learning). Only $11 \%$ continued to attend school after 5 years of primary education. 2.5\% of householders, some old ones, are illiterate. About 9\%, again old people, could learn writing and reading through attending the courses, which were organised by the state to eliminate the illiteracy some decades ago.

The family size of intervied householders is usually small with maximum 2 children. $69 \%$ of families consist of 4 or less persons. $30 \%$ consist of 5-7 persons and only 1 family consisted of 8 people.

Another criterion for evaluation of the development possibilities and economic situation is the size of holdings. While 3 householders do not fulfil any agricultural activity, the rest aquire a revenue from agriculture. 5 householders are landless. Cultivated area of 53\% of householders is below 5 ha. $23 \%$ of householders operate on $5.1-10$ ha of land. $18 \%$ cultivate 10.1-20 ha, and only 3 householders out of the total of 80 interviewed have more than 20 ha. An average area of a farm is 4.9 ha.

Land mobility through tenancy and sharecropping is not very common. However, only $50 \%$ of householders cultivate their own area, while the rest either get land for use as tenants or share-croppers or lease out their land in order to get rent.

Besides the land ownership, another indicator which shows the situation within the rural sector is the ownership of livestock. So, while 5 householders were landless, 22 had no livestock. Next, 41 interviewees (51\%) had no cows. Cows are raised mostly for meeting the needs of the family. $35 \%$ of householders have 1-4 cows, while $11 \%$ have 5-10 cows and only 2 householders have more than 11 cows. On the other hand, only $12.5 \%$ of the families raise sheep and $17.5 \%$ have goats. This reveals the diminishing role of animal husbandry in the region, previously dominated by this branch of rural economy.

The mechanisation of agriculture is not satisfactory. Having tractors is irrational since the size of holdings is usually small. $72 \%$ of the householders do not have a tractor. But those who posses tractors face another problem: the lack of spare parts and complementary machinery.

Availability of electrical tools at home was also asked in order to determine the property of the householders. $95 \%$ of the households have refrigerator, $19 \%$ - vacuum cleaner, and $89 \%$ TV receiver (10\% black-and-white TV).

We have tried to estimate the level of incomes by asking to compare the level of life of a particular farmer with his neighbours' and other dwellers' of the given settlement. 13 householders considered themselves as "wealthy" 
regarding the general level of income in the settlement they lived in. 48 householders said that their level of living was at the medium level and 19 estimated their income level as lower than the others'.

56 householders defined themselves as farmers, but only 40 get their revenue only from agricultural activities. Thus the majority receive incomes also from non-agricultural sources. Only three persons do not work in agriculture. 14 work independently in service sector and 15 persons are retired and get pension from several social security institutions. 4 persons work as labourers.

77 landowners need additional labour force for agricultural activities. 39 use exclusively family work. 33 householders employ agricultural workers when they need and 2 use only hired labourers at their farms.

\section{INPUTS USE IN AGRICULTURE}

Farmers are well aware of the importance of inputs use in increasing land productivity. Therefore they pay great attention to provision of fertilisers, plant protection materials and veterinary services. The purchasing power of the farmers, however, is usually not sufficient and they claim that they can not use inputs, especially fertilisers, adequately. The percentage of householders who do not use fertiliser and other agrochemicals regularly is respectively 16 and 19\%. The rest use these inputs either from the beginning of their agricultural activity or at least for a couple of years.

In order to learn the approach of the farmers to the inputs use, the question "Does the productivity increase parallel to the increase of input usage?" was asked. 85\% of the householders answered the question affirmatively. Only $11 \%$ rejected that idea and mentioned the negative effects of excess inputs usage.

Another reason determining the inputs usage was money $(40 \%$ of answers). "Suggestions of the extension service" and "soil analysis" represented $17 \%$ and $7 \%$ of the answers respectively. Poor farmers plan to increase agrochemical usage whenever they get enough money. Farmers who have adequate financial possibilities use agrochemicals, especially fertilisers, at a maximum level. Some rich and conscious farmers prefer, on the other hand, to make the nutrients in the soil of their land analysed. Though the capacity of all the 69 laboratories in Turkey attains one million tests yearly, only 350-400 thousand analyses are in fact carried out. These findings indicate that fertilizer use is haphazard in Turkey and in the research area as well.

$54 \%$ of interviewed householders said that they can not use enough of fertiliser due to high prices. $28 \%$ said that they apply sufficient amounts of fertiliser. $40 \%$ of the anwers were that the influence of insecticides/pesticides is not satisfactory, while $47.5 \%$ expected good results from the plant protection means. The problem is, in fact, not the decrease in effectiveness 
of the insecticides, but the increased resistance of the diseases and pests because of excess usage. The larger doses they use the bigger the decrease of sensitivity of the pest to the plant protection chemicals. As a result higher doses are given more frequently and thus the circle continues.

The use of insecticides and pesticides per hectare (average of 500-600 gr./ha) is very limited in Turkey compared to the developed countries. The usage is, however, not homogeneous over the country. In some regions consumption of pesticides and insecticides is more than the average and in some regions it is vice versa. In the Mediterranean Region the consumption of pesticides/insecticides reaches about the half of the total consumption of the country. Since the consumption of chemicals is at a considerably high level in the region, environmental pollution is also possible. In order to learn the opinions of farmers in that subject the question "Are there disadvantages to increased chemicals usage?" was asked. $85 \%$ of householders answered that question affirmatively and explained the damage danger from excess inputs use. Some people saw the problem in the increase of production costs. No one thinks that he uses excess input. However, everybody, except of some householders who use sufficient input according to their opinion, wants to use more inputs for increasing the productivity. This brings the hazard of pollution, maybe not dangerous today, but certainly so in the future.

\section{COOPERATION AND COMMUNICATION ATTITUDES}

In distinction to the solidarity and traditional social security, economic co-operation is not very common in Turkish villages. To establish co-operatives and to be a member of a co-operative is considered to constitute an example of collaboration attitude of the rural people. Co-operatives, such as credit or service co-operatives, have been always under the state control in Turkey since their establishment. Many farmers do not believe in the importance of the agricultural co-operatives and they are not eager to become a member of a co-operative. The situation in the research area, however, is not so dramatic and only $35 \%$ of the householders do not belong to any co-operative. $13 \%$ of the householders on the other hand, are the members of several co-operatives.

Communication in the rural areas is developed to a great extent. Not only very suitable transportation possibilities, but also the mass media facilities help rural population to follow innovations and the news from the country and from the world as well.

Reading and writing abilities are not seen necessary in rural life and the dwellers have no reading habit. The rate of newspapers' readers is, therefore, also low, $25 \%$ of householders do not read newspapers and $75 \%$ read one or more newspapers daily or whenever they find any press to read. $35 \%$ of householders buy newspapers daily or sometimes, while $40 \%$ read it only in village coffee houses or elsewhere. 
TV and radio is available almost in every house. $97 \%$ of householders follow the news from TV and radio regularly. $23 \%$ watch generally only the country news, while $74 \%$ are interested in the world news as well.

\section{PROBLEMS AND CONSIDERATIONS FOR THE RURAL LIFE}

Difficulties of the rural life, low level of income, less opportunities from many points of view, as compared to the city life, create main problems for the peasants. Interviewed householders, however, did not mention these problems at all. $36 \%$ of them say the main problem is the scarcity of irrigation water. Insufficient amount of water limits the use of inputs and as a result productivity declines and consequently agricultural revenue becomes low.

For another $25 \%$ of householders the high inputs prices and interest rates are perceived as the main problems. Nevertheless, $13 \%$ of householders stated that they do not face any important problem and they are satisfied with their agricultural activity.

The opinion of householders with respect to today's life compared to the life in the pastime was asked as well. $83 \%$ of interviewed householders expressed that today's life is much better because the technology developed, thus facilitating the life and decreasing the differences between rural and urban areas. Availability of electricity, drinking water and telephone communication in the villages, possibility of using electrical tools at home, increased communication and transportation were seen as the factors of improvement.

13\% of interviewed householders complained about today's life. They mentioned the degenerating human relations, weakening ties among relatives and neighbours, and increasing selfishness of people as the reasons for the worsening life quality. 
